Supplement of Atmos. Chem. Phys., 15, 951-972, 2015

http://www.atmos-chem-phys.net/15/951/2015/

doi:10.5194/acp-15-951-2015-supplement

(C) Author(s) 2015. CC Attribution 3.0 License.

(c) (i)

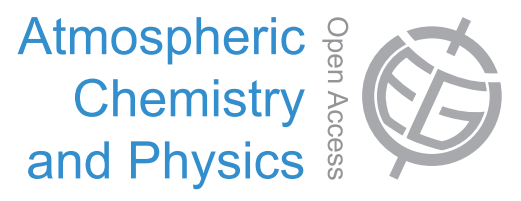

Supplement of

\title{
Atmospheric wet and dry deposition of trace elements at 10 sites in Northern China
}

\author{
Y. P. Pan and Y. S. Wang \\ Correspondence to: Y. P. Pan (panyuepeng@mail.iap.ac.cn) and Y. S. Wang (wys@mail.iap.ac.cn)
}



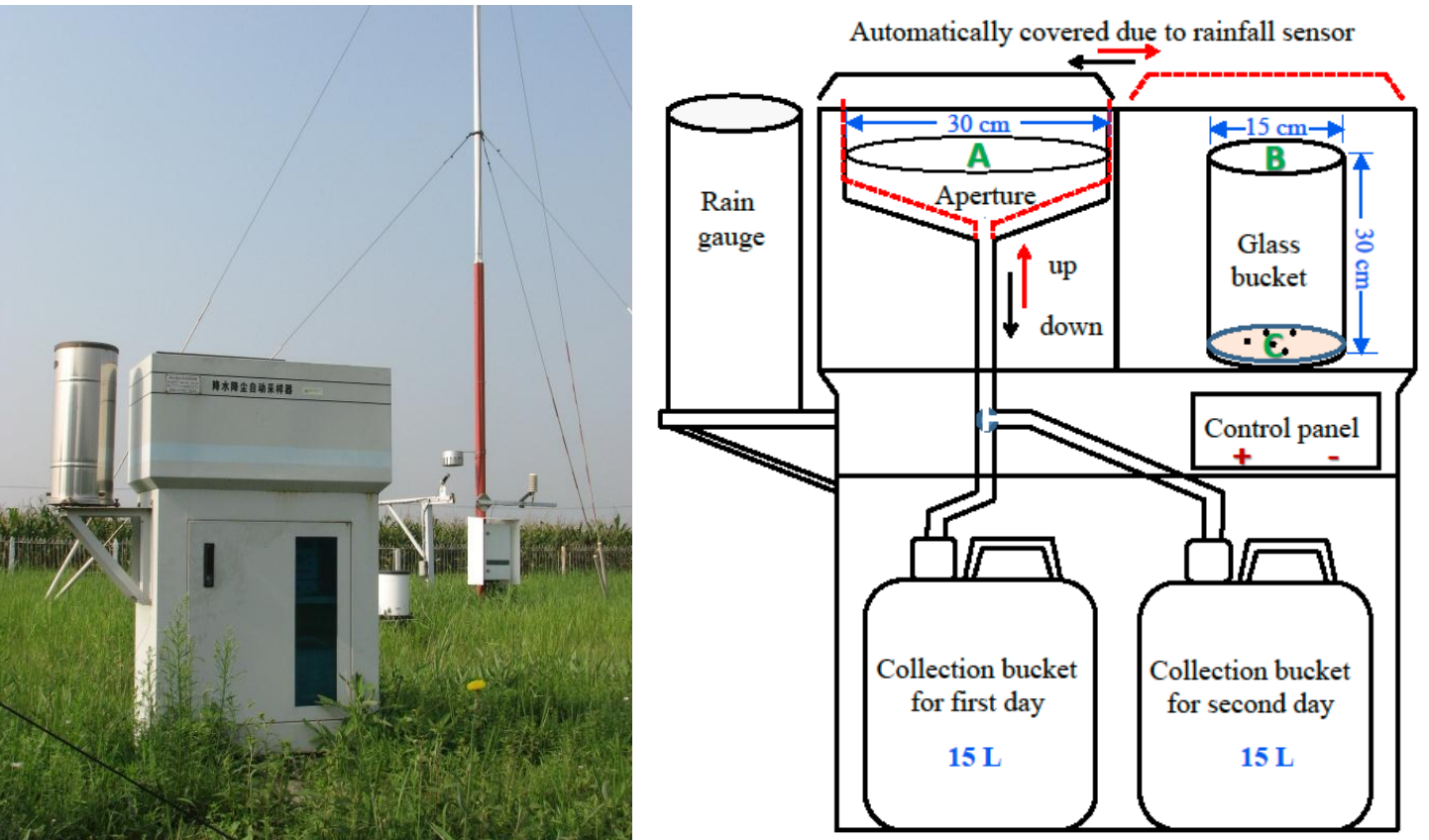

2 Figure S1. The automated wet and dry deposition sampler used in this study. The

3 agricultural station of Yucheng in Shandong Province (left) and a schematic diagram

4 of the sampler with the main apparatus (right): rainfall sampler (a), dry deposition

5 bucket (b), and PUF filter for sampling dry deposited particles (c).

6
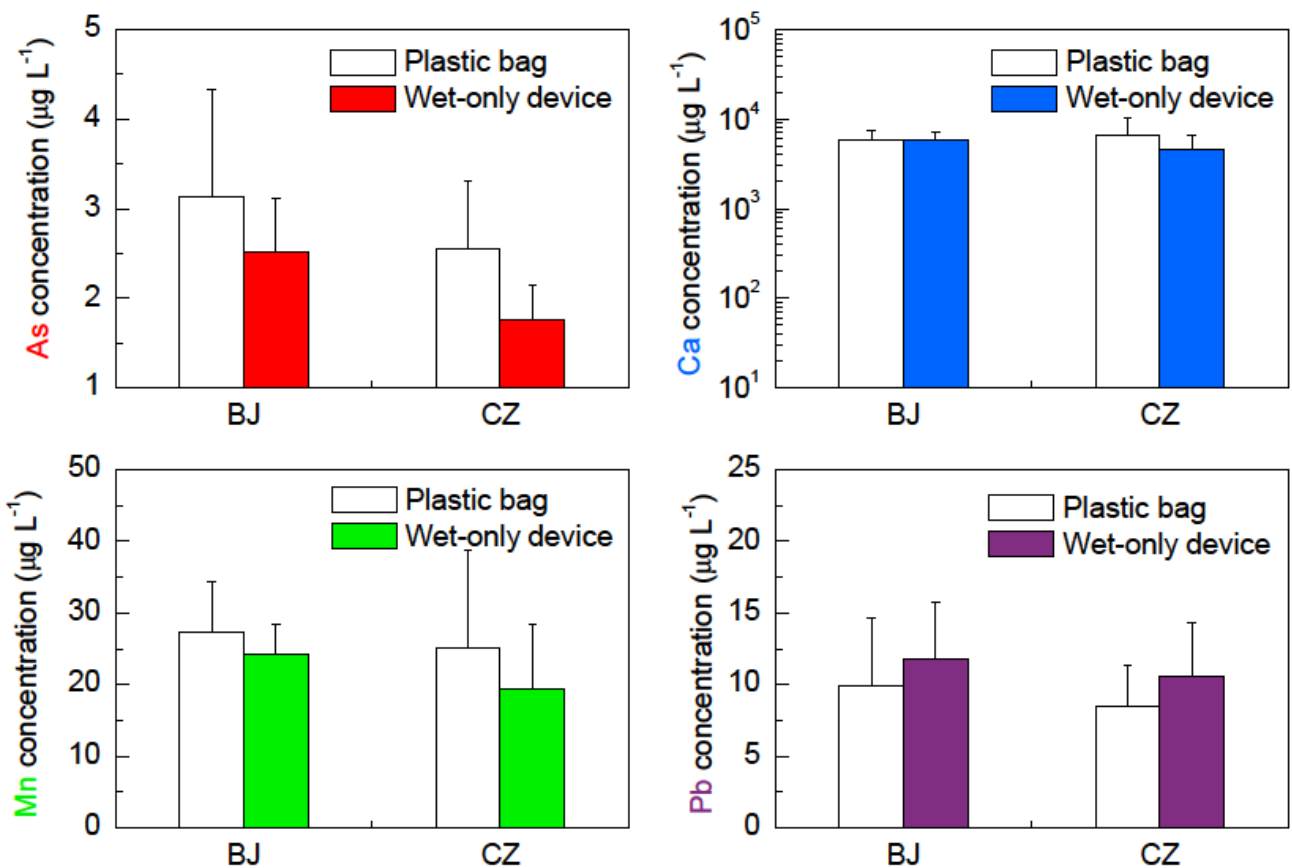

8 Figure S2. Rainfall metal concentrations concurrently collected by the plastic bag and

9 the automatic sampler at the sites of $\mathrm{BJ}(n=5)$ and $\mathrm{CZ}(n=4)$. Figure was adopted from

$\underline{\operatorname{Pan}(2010)}$. 


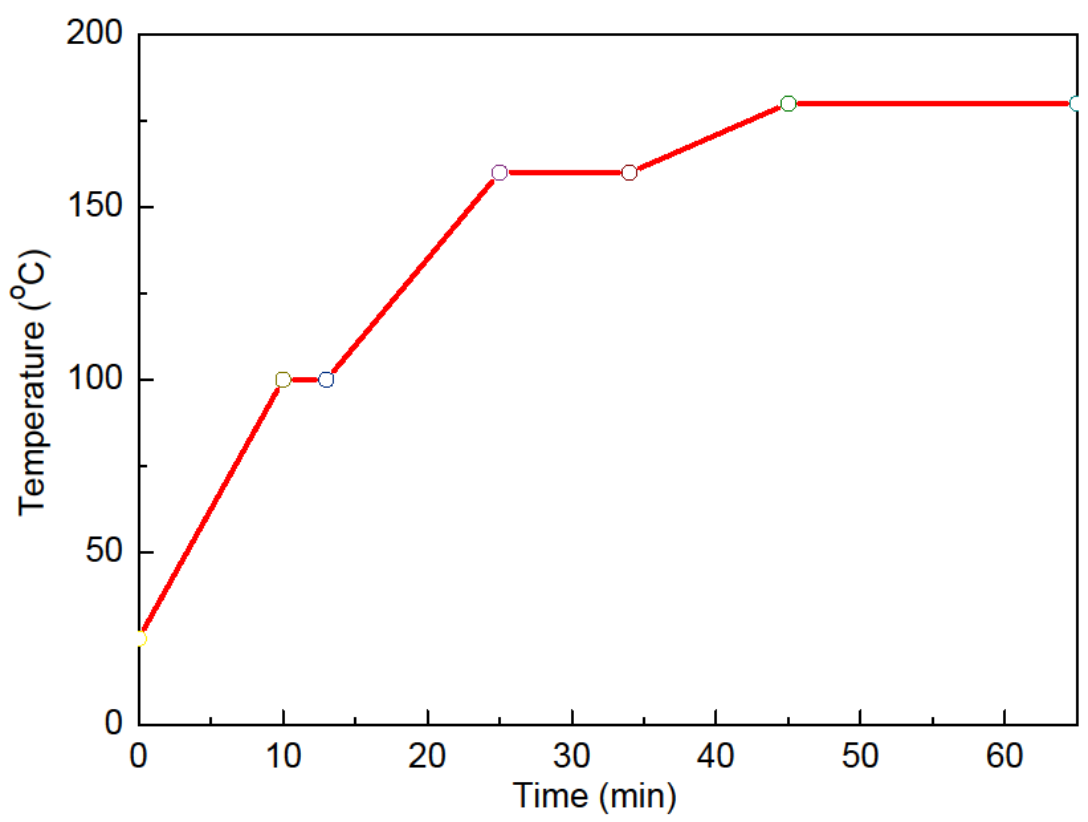

13 Figure S3. Temperature-controlled microwave digestion of a PUF filter with 14 dry-deposited particles using $5 \mathrm{ml} \mathrm{HNO}_{3}, 2 \mathrm{ml} \mathrm{H}_{2} \mathrm{O}_{2}$ and $0.2 \mathrm{ml} \mathrm{HF}$. Method was 15 adopted from $\underline{\text { Pan et al. (2010). }}$

16

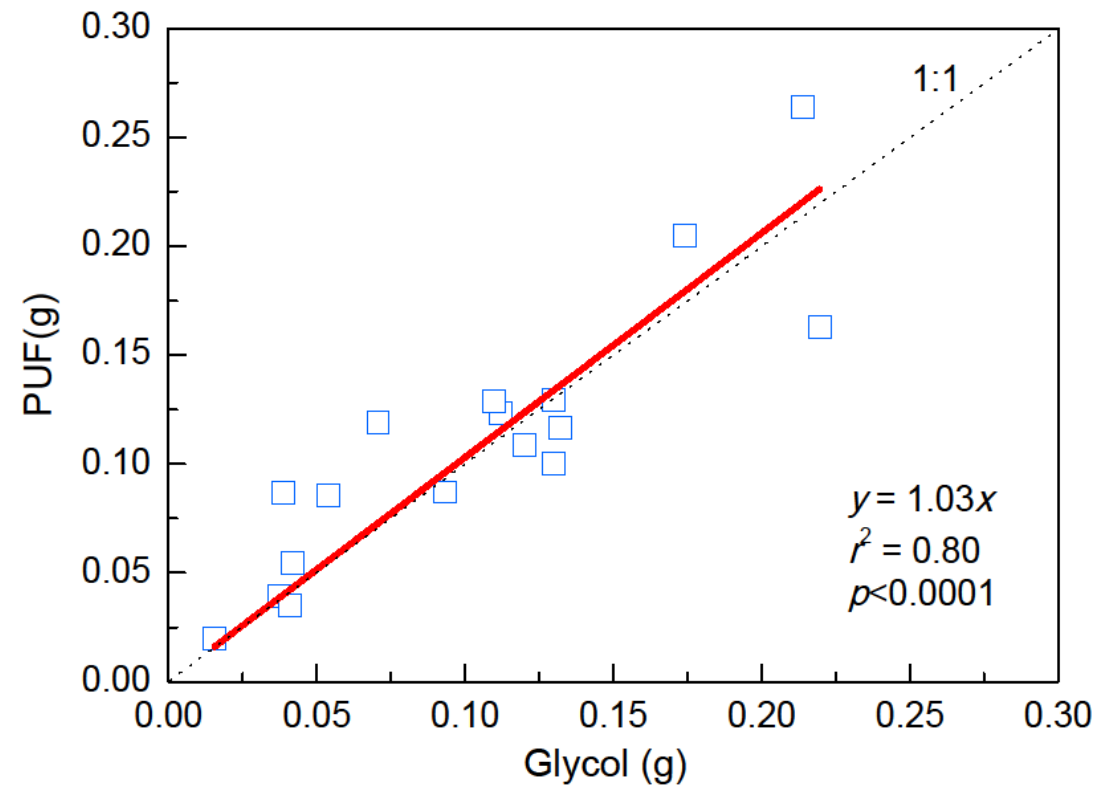

18 Figure S4. Comparison of atmospheric dry deposited mass collected by different 19 surrogate surface on a monthly basis at the BJ and CZ sites. Figure was adopted from $20 \quad$ Pan et al. (2010). 


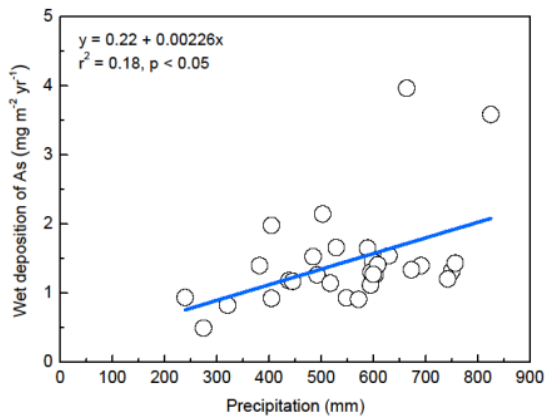

23
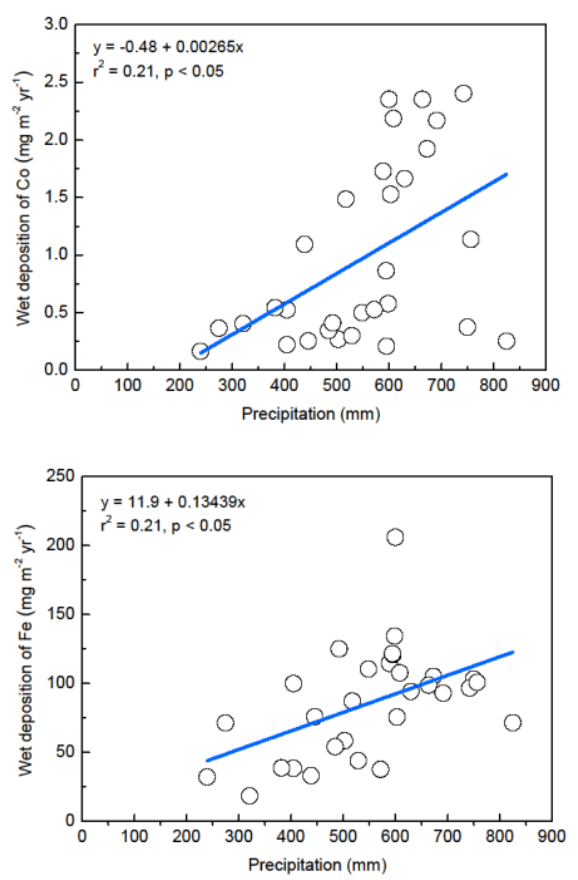

24

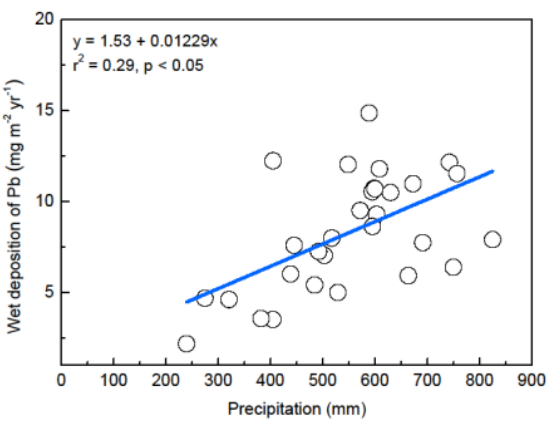

25

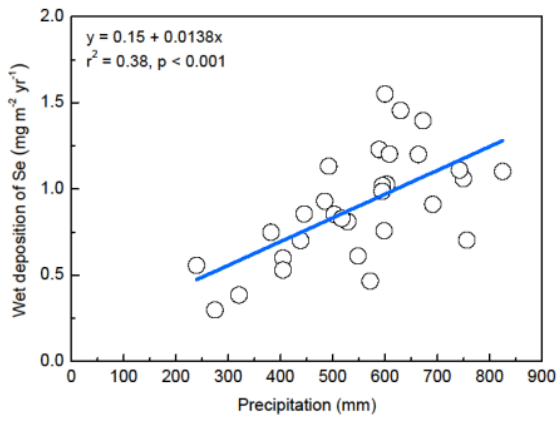

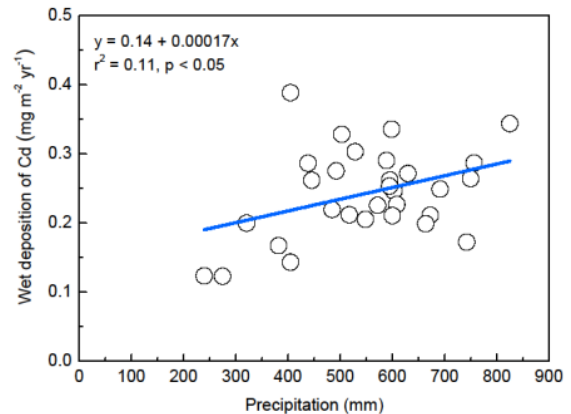
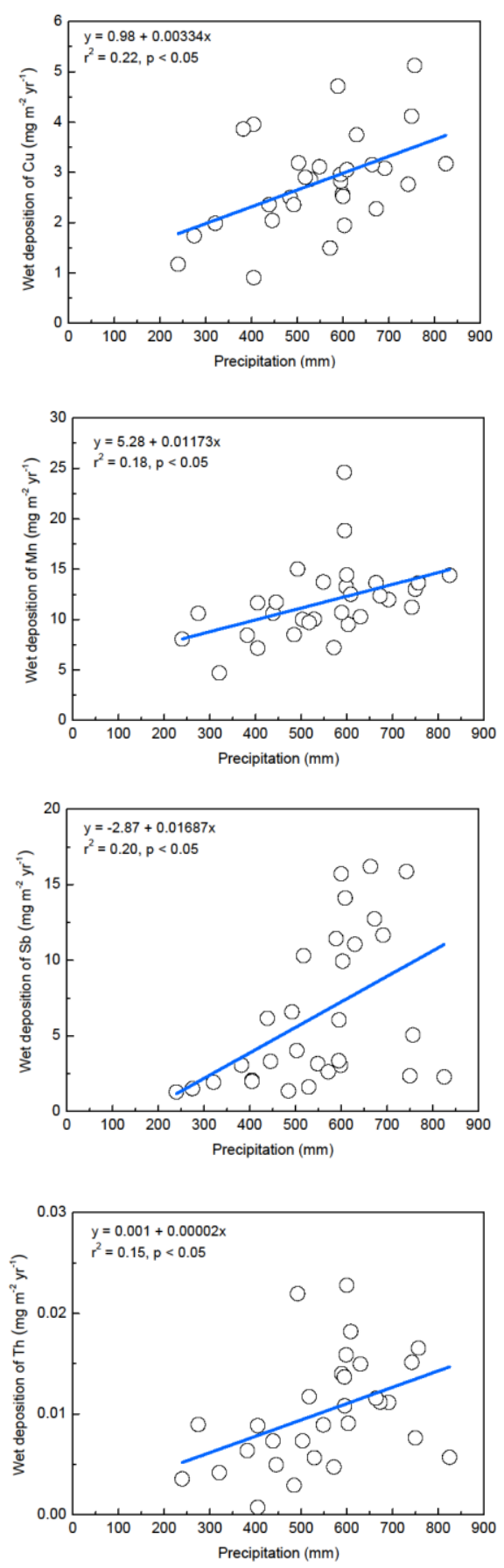

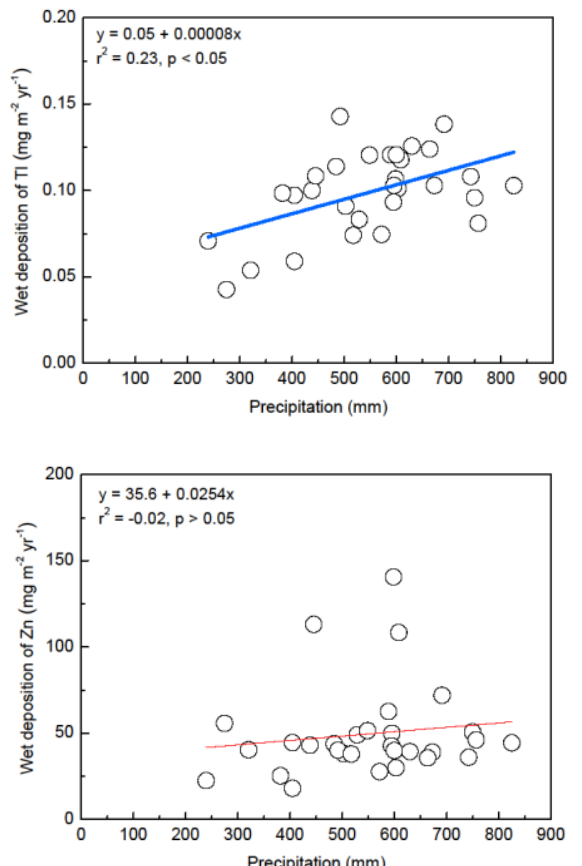

28

29

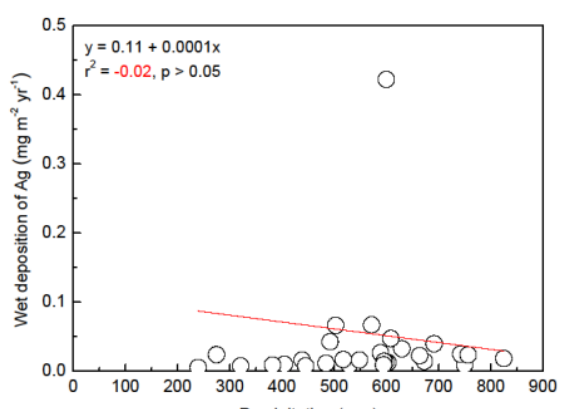
Precipitation $(\mathrm{mm})$

30

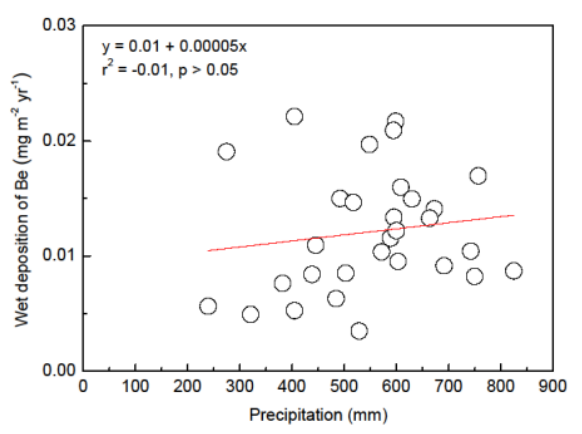

31

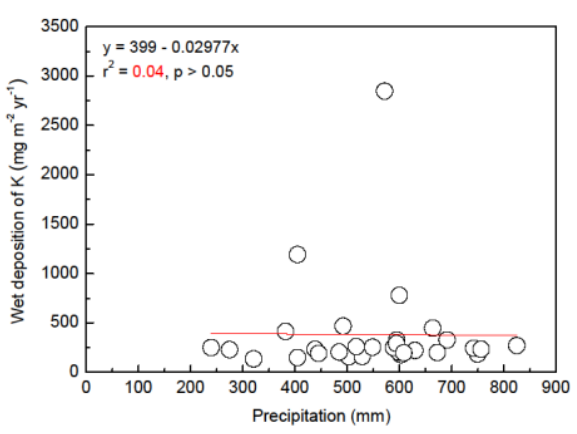

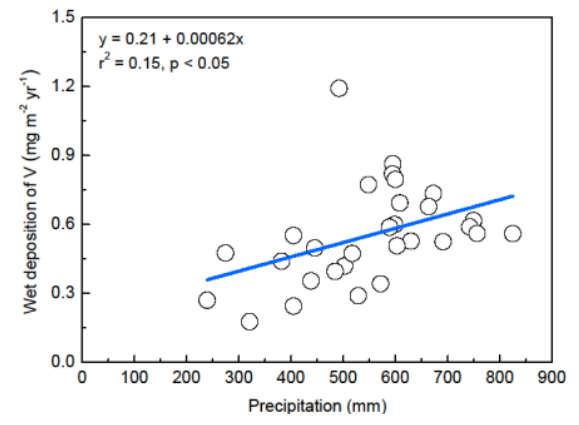
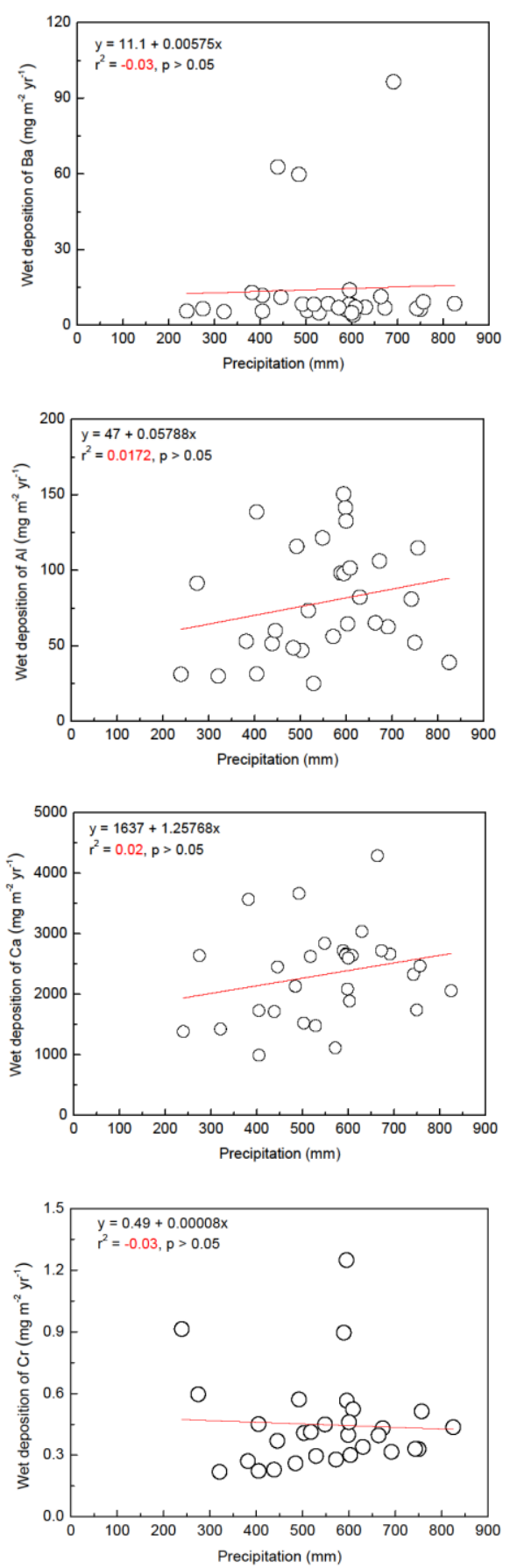

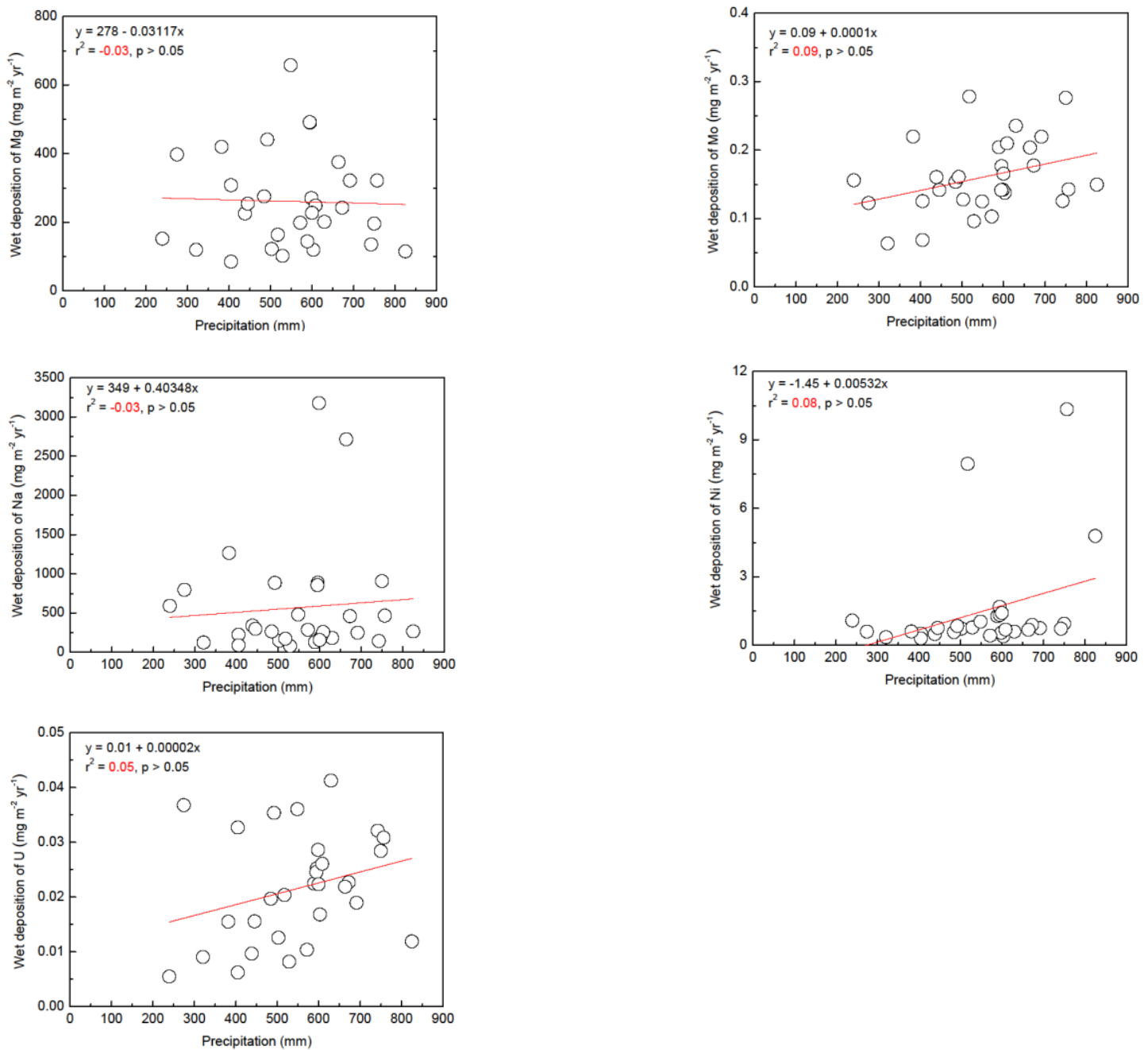

Figure S5. Annual wet deposition fluxes of trace elements vs. precipitation in Northern China.

\section{References}

Pan, Y.: Atmospheric wet and dry deposition fluxes of trace elements measured in Jing-Jin-Ji area, Northern China, Ph.D thesis, Institute of Atmospheric Physics, Chinese Academy of Sciences, Beijing, 167 pp., 2010.

Pan, Y. P., Wang, Y. S., Yang, Y. J., Wu, D., Xin, J. Y., and Fan, W. Y.: Determination of trace metals in atmospheric dry deposition with a heavy matrix of PUF by inductively coupled plasma mass spectroscopy after microwave digestion, Environ. Sci., 31, 553-559 (in 